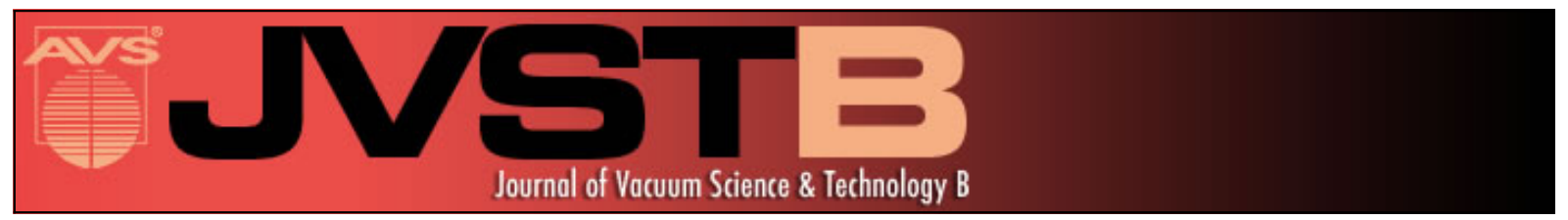

\title{
Direct epitaxial growth of submicron-patterned SiC structures on $\mathrm{Si}(001)$
}

Gyu-Chul Yi, G. Eres, and D. H. Lowndes

Citation: Journal of Vacuum Science \& Technology B 17, 2600 (1999); doi: 10.1116/1.591029

View online: http://dx.doi.org/10.1116/1.591029

View Table of Contents: http://scitation.aip.org/content/avs/journal/jvstb/17/6?ver=pdfcov

Published by the AVS: Science \& Technology of Materials, Interfaces, and Processing

\section{Articles you may be interested in}

Effects of $6 \mathrm{H}$ - SiC surface reconstruction on lattice relaxation of AIN buffer layers in molecular-beam epitaxial growth of $\mathrm{GaN}$

Appl. Phys. Lett. 81, 5141 (2002); 10.1063/1.1533855

Structural properties of undoped and doped cubic GaN grown on $\mathrm{SiC}(001)$

J. Appl. Phys. 91, 4983 (2002); 10.1063/1.1456243

Advances in the molecular-beam epitaxial growth of artificially layered heteropolytypic structures of SiC Appl. Phys. Lett. 77, 2418 (2000); 10.1063/1.1311955

Optimized structural properties of wurtzite $\mathrm{GaN}$ on $\mathrm{SiC}(0001)$ grown by molecular beam epitaxy

J. Vac. Sci. Technol. A 18, 1915 (2000); 10.1116/1.582445

Molecular beam epitaxy growth of $\mathrm{SiC}$ on $\mathrm{Si}(111)$ from silacyclobutane

J. Vac. Sci. Technol. B 16, 1305 (1998); 10.1116/1.590006

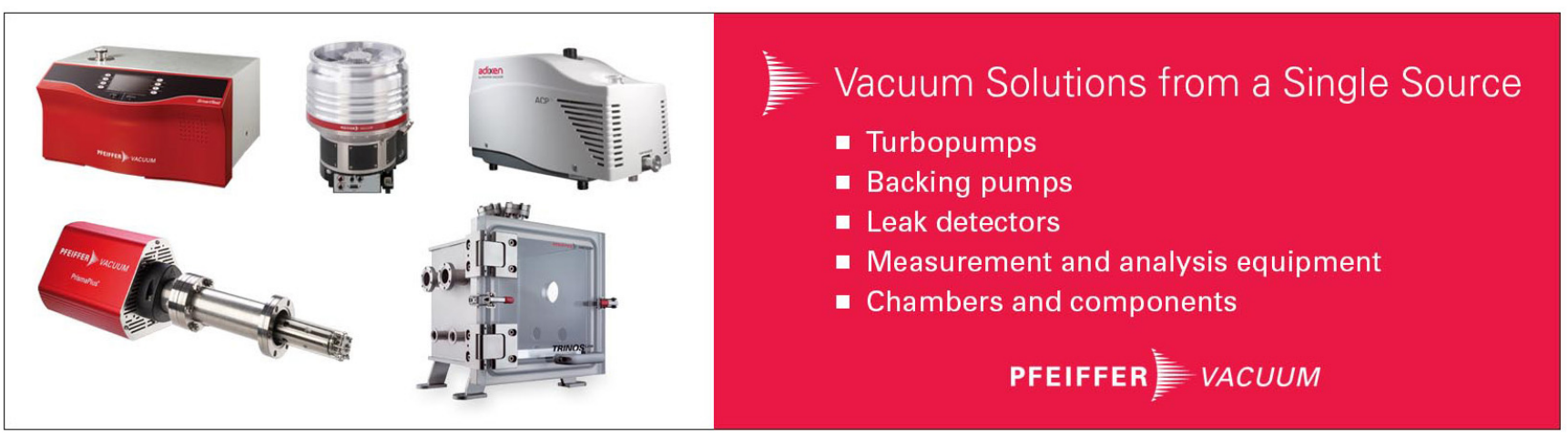




\title{
Direct epitaxial growth of submicron-patterned $\mathrm{SiC}$ structures on $\mathrm{Si}(001)$
}

\author{
Gyu-Chul Yi, ${ }^{\text {a) }}$ G. Eres, and D. H. Lowndes \\ Solid State Division, Oak Ridge National Laboratory, Oak Ridge, Tennessee 37831
}

(Received 26 April 1999; accepted 13 August 1999)

\begin{abstract}
We report on the direct epitaxial growth of submicron-patterned $\mathrm{SiC}$ structures on $\mathrm{Si}(001)$ substrates using supersonic molecular jet epitaxy and resistless e-beam lithography. Prior to $\mathrm{SiC}$ film growth, an electron beam was scanned on hydrogen-passivated Si substrates in order to produce silicon oxide lines with widths $\geqslant 60 \mathrm{~nm}$. The $\mathrm{SiC}$ nucleation and growth rates were significantly reduced on the oxidized regions during the subsequent supersonic jet epitaxial growth of $\mathrm{SiC}$, which yielded epitaxial, submicron-patterned $\mathrm{SiC}$ films. The effects of the growth temperature and e-beam dose on the $\mathrm{SiC}$ growth and pattern linewidth are discussed. (C) 1999 American Vacuum Society.

[S0734-211X(99)00906-3]
\end{abstract}

\section{INTRODUCTION}

There is much interest in the growth and processing of wide-band-gap semiconductors for high-temperature electronic device applications. ${ }^{1-4}$ For device fabrication, submicron patterning of materials is increasingly needed. However, the high chemical stability of the wide-band-gap semiconductors such as $\mathrm{SiC}$ and $\mathrm{GaN}$ makes it difficult to use conventional etching techniques. ${ }^{5}$ Alternative microfabrication techniques have been developed using plasma-based reactive ion etching (RIE) to overcome the high chemical stability. ${ }^{5,6}$ However, RIE for $\mathrm{SiC}$ often results in surface damage as well as contamination from the cathode material through a micromasking effect. ${ }^{6}$

The residual contamination and material degradation caused by RIE can be eliminated by selective area epitaxial growth. ${ }^{7}$ For selective area epitaxial growth of $\mathrm{SiC}$, conventional chemical vapor deposition has been employed using a submicrometer-thick silicon oxide layer to impede nucleation. ${ }^{8,9}$ However, high growth temperatures above $1000{ }^{\circ} \mathrm{C}$ are required, which resulted in significant degradation of the microstructures. ${ }^{9}$ The degradation is more severe for a thinner silicon oxide mask layer, which results in difficulty in making submicron-scale structures. This article reports on the direct fabrication of $\mathrm{SiC}$ microstructures with resolution $\geqslant 130 \mathrm{~nm}$ using supersonic molecular jet (SMJ) epitaxy and resistless e-beam lithography.

The resistless patterning of semiconductor surfaces is of particular interest for developing all-dry fabrication methods for thin-film structures. ${ }^{10-12}$ For the resistless patterning, scanning electron-beam lithography of a surface hydride layer adsorbed on silicon has been developed. ${ }^{13}$ The combination of hydride patterning and SMJ growth prevents exposure of the substrate to atmospheric and process-related contaminants and degradation of the microstructures due to the contaminants or attempts at surface cleaning.

SMJ epitaxy has been employed as a hyperthermal growth technique to reduce the $\mathrm{SiC}$ growth temperature. ${ }^{14,15}$ During supersonic free-jet expansion into a vacuum chamber, indi-

${ }^{a)}$ Permanent address: Dept. of Materials Science and Engineering, Pohang Univ. of Science and Technology, Pohang 790-784, Korea; electronic mail: gcyi@postech.ac.kr vidual gas molecules undergo a large number of collisions and in this process the enthalpy of the gas decreases while the kinetic energy of the molecules increases. Higher kinetic energies of film-growth molecules can be obtained by seeding a heavy reactant methylsilane gas $\left(\mathrm{SiH}_{3} \mathrm{CH}_{3}\right)$ in a light carrier gas (He). In the expansion, both components of the gas mixture are accelerated to nearly the same velocity and the kinetic energy of the heavy reactant molecules increases. For the $10 \% \mathrm{SiH}_{3} \mathrm{CH}_{3}$ in the $\mathrm{He}$ mixture used in this research, the average translational kinetic energy of $\mathrm{SiH}_{3} \mathrm{CH}_{3}$ molecules is calculated to be $0.36 \mathrm{eV}$. Due to the hyperthermal kinetic energy and high central flux of the $\mathrm{SiH}_{3} \mathrm{CH}_{3}$ molecules, the growth temperature for $\mathrm{SiC}$ films could be reduced as low as $700{ }^{\circ} \mathrm{C} .^{16}$

\section{EXPERIMENTAL PROCEDURE}

The hydrogen-passivated $\mathrm{Si}$ substrates were prepared using the following procedure. The $\mathrm{Si}$ substrates were degreased using trichloroethylene, acetone, and isopropylalcohol. After rinsing with deioinized water, the substrates were oxidized in an ultraviolet ozone reactor and then were etched in $4 \%$ dilute $\mathrm{HF}$ for $30 \mathrm{~s}$ to produce a hydride-passivated surface immediately prior to loading them in the scanning electron microscope (SEM) chamber.

Submicron selectivity for the growth of $\mathrm{SiC}$ was created by resistless electron-beam lithography. The e-beam lithography system consists of a commercial SEM configured for external scanning mode. The typical beam currents used were on the order of 40-60 pA. The electron dose was in the range of $0.8-1.3 \mu \mathrm{C} / \mathrm{cm}$. The pressure in the chamber was about $5 \times 10^{-7}$ Torr. The electron beam was scanned over the hydrogen-passivated $\mathrm{Si}(100)$ substrates, resulting in local desorption of hydrogen and subsequent formation of a thin silicon oxide layer due to the presence of residual water vapor in the chamber. ${ }^{13}$

After patterning, the samples were immediately loaded into the SMJ growth chamber. The hydrogen on the Si surface was desorbed by thermal annealing above $500{ }^{\circ} \mathrm{C}$. The $\mathrm{SiC}$ films were grown on the patterned $\mathrm{Si}(001)$ substrates in an ultra-high-vacuum chamber with a typical base pressure of mid- $10^{-9}$ Torr. The supersonic molecular jet of $\mathrm{SiH}_{3} \mathrm{CH}_{3}$ was generated via a nozzle with its orifice diameter of 200 


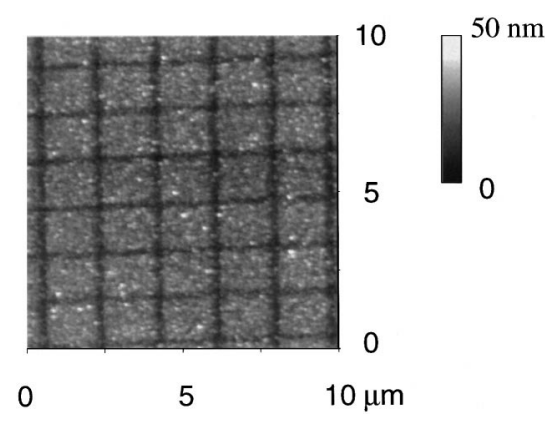

FIG. 1. AFM image of patterned $\mathrm{SiC}$ structures grown on $\mathrm{Si}(100)$. The microstructures were grown at $750{ }^{\circ} \mathrm{C}$ for $15 \mathrm{~min}$ at a pressure of $0.5 \mathrm{mTorr}$.

$\mu \mathrm{m}$ and normally incident on the substrate. During the deposition, the main chamber pressure was monitored using a capacitance manometer. A constant beam flux was maintained at the chamber pressure of 0.5-1.0 mTorr using a needle valve. The substrates were radiatively heated using a BN-coated ceramic heater supported on a Ta holder. The growth temperatures investigated in this research ranged from 680 to $900{ }^{\circ} \mathrm{C}$ as monitored by an optical pyrometer.

\section{RESULTS AND DISCUSSION}

The surface topography of submicron SiC structures was investigated using atomic force microscopy (AFM). After the thin silicon oxide mask pattern was fabricated using an e-beam line dose of $0.9 \mu \mathrm{C} / \mathrm{cm}$ on the H-passivated Si substrate, the $\mathrm{SiC}$ film (Yi056) was grown on the patterned $\mathrm{Si}(100)$ at $750{ }^{\circ} \mathrm{C}$ for $15 \mathrm{~min}$ at a pressure of $0.5 \mathrm{mTorr}$. As shown in Fig. 1, well-fabricated grid $\mathrm{SiC}$ microstructures were obtained using the resistless electron-beam lithography and SMJ. The typical thickness (height) of the structures is $10-20 \mathrm{~nm}$ and the average surface roughness is $3-4 \mathrm{~nm}$. The AFM image structure with continuous lines is as narrow as $200 \mathrm{~nm}$, as Fig. 1 shows. The growth selectivity results from the lower nucleation and growth rate of $\mathrm{SiC}$ on the silicon oxide layer than on Si. Similar behavior was previously observed in the Ge/Si system. $^{7}$

The linewidths of the $\mathrm{SiC}$ microstructures were controlled by the e-beam dose. Figure 2 shows AFM images of the $\mathrm{SiC}$ microstructures fabricated with doses of 0.8 (Yi052) and 1.3 (Yi055) $\mu \mathrm{C} / \mathrm{cm}$. For the higher dose, the linewidth broadened to $350 \mathrm{~nm}$, which may be due to increased hydrogen

(a)

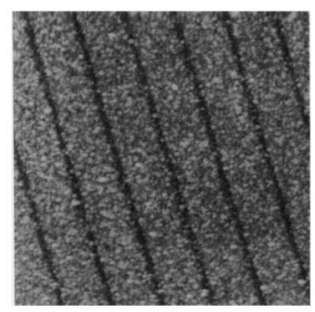

(b)

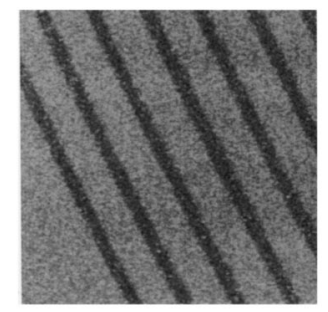

FIG. 2. AFM image of $\mathrm{SiC}$ microstructures grown on $\mathrm{Si}(100)$ (figure dimension $=8.5 \times 8.5 \mu \mathrm{m}^{2}$ ). Patterning using electron line doses of (a) 0.8 and (b) $1.5 \mu \mathrm{C} / \mathrm{cm}$ resulted in linewidths of 130 and $350 \mathrm{~nm}$, respectively.

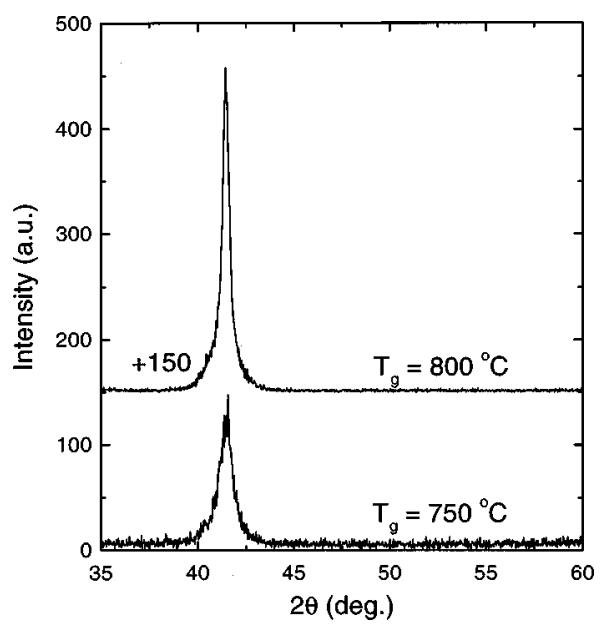

FIG. 3. Typical XRD data of $\mathrm{SiC}$ films grown at temperatures $\left(T_{g}\right)$ of $750{ }^{\circ} \mathrm{C}$ and $800{ }^{\circ} \mathrm{C}$. Only an XRD peak of $3 \mathrm{C}-\mathrm{SiC}(200)$ is shown.

desorption caused by increased heating. The variation of the linewidth results presumably from the $\pm 5 \%$ instability of the patterned e-beam current.

The crystallinity of the as-grown patterned films was characterized using $\mathrm{X}$-ray diffraction (XRD) measurements. Figure 3 shows typical XRD results for the films grown at 750 and $800{ }^{\circ} \mathrm{C}$. The only XRD peak observed was at $41.4^{\circ}$, corresponding to $3 \mathrm{C}-\mathrm{SiC}(002)$. This shows that the submicron-patterned $\mathrm{SiC}$ has crystallized at $750{ }^{\circ} \mathrm{C}$, with the low-temperature crystallization presumably assisted by the hyperthermal kinetic energy of the supersonic jet. ${ }^{16}$

The submicron patterns of $3 \mathrm{C}-\mathrm{SiC}$ on $\mathrm{Si}(100)$ depended significantly on the growth temperature. At temperatures below $700{ }^{\circ} \mathrm{C}$, the patterns were difficult to find because the films were very thin everywhere. Increasing the growth temperature to $750-780{ }^{\circ} \mathrm{C}$ produced thicker films with easily observable patterns. This suggests that the silicon oxide patterns generated by resistless lithography maintain their integrity up to nearly $800^{\circ} \mathrm{C}$. However, $\mathrm{SiC}$ films grown above $800{ }^{\circ} \mathrm{C}$ did not show any pattern. The degradation of the patterns at temperatures above $800{ }^{\circ} \mathrm{C}$ occurs presumably by decomposition of silicon oxide and formation of volatile SiO. According to Edgar et al., ${ }^{9}$ a $284-n m-t h i c k$ silicon oxide layer was degraded at $950{ }^{\circ} \mathrm{C}$. In our experiments, the degradation of the much thinner $(\sim$ few $n m)$ oxide layers started at the relatively low temperature of $800{ }^{\circ} \mathrm{C}$.

\section{CONCLUSIONS}

In conclusion, direct epitaxial growth of submicronpatterned $\mathrm{SiC}$ was carried out on $\mathrm{Si}(001)$ using supersonic molecular jet epitaxy and resistless electron-beam lithography. The optimum growth temperature range was from 730 to $780{ }^{\circ} \mathrm{C}$. For temperatures above $800{ }^{\circ} \mathrm{C}$, the microstructures could not be fabricated due to degradation of the silicon oxide mask. SiC microstructures with linewidths of 130-350 $\mathrm{nm}$ were achieved using scanned e-beam doses of $0.8-1.3$ $\mu \mathrm{C} / \mathrm{cm}$. 


\section{ACKNOWLEDGMENTS}

The authors would like to thank Dr. T. G. Thundat, Dr. J.-W. Park, and Dr. F. Y. C. Hui for helpful discussions. This research was sponsored by the Oak Ridge National Laboratory, which is managed by the Lockheed Martin Energy Research Corporation for the U.S. Department of Energy, under Contract No. DE-AC05-96OR22464.

${ }^{1}$ J. H. Edgar, J. Mater. Res. 7, 235 (1992).

${ }^{2}$ H. Morkoç, S. Strite, G. B. Gao, M. E. Lin, B. Sverdlov, and M. Burns, J. Appl. Phys. 76, 1363 (1994).

${ }^{3}$ H. Matsunami and T. Kimoto, Mater. Sci. Eng., R. 20, 125 (1997).

${ }^{4}$ T. Fuyuki, T. Hatayama, and H. Matsunami, Phys. Status Solidi B 202, 359 (1997).
${ }^{5}$ P. H. Yih, V. Saxena, and A. J. Steckl, Phys. Status Solidi B 202, 605 (1997).

${ }^{6}$ A. J. Steckl and P. H. Yih, Appl. Phys. Lett. 60, 1966 (1992).

${ }^{7}$ G. Eres, F. Y. C. Hui, T. Thundat, and D. C. Joy, J. Vac. Sci. Technol. B 15, 2934 (1997).

${ }^{8}$ Y. Ohshita and A. Ishitani, J. Appl. Phys. 66, 4535 (1989); Y. Ohshita, Appl. Phys. Lett. 57, 605 (1990).

${ }^{9}$ J. H. Edgar, Y. Gao, J. Chaudhuri, S. Cheema, S. A. Casalnuovo, P. W. Yip, and M. V. Sidorov, J. Appl. Phys. 84, 201 (1998).

${ }^{10}$ J. W. Lyding, T.-C. Shen, J. S. Hubacek, J. R. Tucker, and G. C. Abeln, Appl. Phys. Lett. 64, 2010 (1994).

${ }^{11}$ K. Masu and K. Tsubouchi, J. Vac. Sci. Technol. B 12, 3270 (1994).

${ }^{12}$ E. S. Snow and P. M. Campbell, Appl. Phys. Lett. 64, 1932 (1994).

${ }^{13}$ F. Y. C. Hui, G. Eres, and D. C. Joy, Appl. Phys. Lett. 72, 341 (1998).

${ }^{14}$ L.-Q. Xia, M. E. Jones, N. Maity, and J. R. Engstrom, J. Vac. Sci. Technol. A 13, 2651 (1995).

${ }^{15}$ S. A. Ustin and W. Ho, Mater. Res. Soc. Symp. Proc. 482, 313 (1998).

${ }^{16}$ G.-C. Yi, G. Eres, and D. H. Lowndes (unpublished). 